\title{
Life-threatening Errors with Flecainide Suspension in Children
}

\section{Medical Product Error-Prevention Efforts Need to Be Shared and Harmonized Internationally}

\author{
Michael R. Cohen, RPh, MS, ScD, "and Judy L. Smetzer, RN, BSN ${ }^{+}$
}

\begin{abstract}
These medication errors have occurred in health care facilities at least once. They will happen again-perhaps where you work. Through education and alertness of personnel and procedural safeguards, they can be avoided. You should consider publishing accounts of errors in your newsletters and/or presenting them at your inservice training programs.

Your assistance is required to continue this feature. The reports described here were received through the Institute for Safe Medication Practices (ISMP) Medication Errors Reporting Program. Any reports published by ISMP will be anonymous. Comments are also invited; the writers' names will be published if desired. ISMP may be contacted at the address shown below.

Errors, close calls, or hazardous conditions may be reported directly to ISMP through the ISMP Web site (www.ismp.org), by calling 800-FAIL-SAFE, or via e-mail at ismpinfo@ismp.org. ISMP guarantees the confidentiality and security of the information received and respects reporters' wishes as to the level of detail included in publications.
\end{abstract}

\section{PATIENT-CONTROLLED ANALGESIA BASAL INFUSION OVERDOSE}

A physician prescribed patient-controlled analgesia (PCA) for a postoperative patient by telephone. The prescription was for hydromorphone demand doses of $0.3 \mathrm{mg}$, a lockout interval of 10 minutes, and a basal infusion of $1.5 \mathrm{mg} /$ hour. The new order was entered on a medication administration record (MAR) by nursing, but the basal infusion was misread as $15 \mathrm{mg} /$ hour and, thus, entered incorrectly. The original order was used as reference when first programming the pump, so the correct basal dose of $1.5 \mathrm{mg}$ was programmed. Then, after the patient ambulated to the bathroom, the pump was not plugged back into the electrical socket. The pump ran out of battery power; instead of plugging the pump in, a new pump was used. This time, the MAR was used to guide the programming, and the pump was set to deliver $15 \mathrm{mg}$ not $1.5 \mathrm{mg}$ of hydromorphone each hour. An hour later, the patient was found unresponsive. He was given naloxone and transferred to a critical care unit, where he required another dose of naloxone and recovered.

Despite the transcription error that resulted in a basal dose of $15 \mathrm{mg} /$ hour instead of $1.5 \mathrm{mg} /$ hour being entered on the MAR, use of a smart pump with dose error-reduction software (DERS) would have alerted the nurse to the error while the pump was being programmed. In fact, a basal dose of $15 \mathrm{mg} /$ hour should result in a hard stop without the ability to override the warning. An independent double-check of the PCA settings also may have caught the error.

Because the syringe of hydromorphone was obtained from an automated dispensing cabinet, there was no pharmacy label listing the patient-specific basal dose of $1.5 \mathrm{mg} /$ hour for reference. Basal infusions are not recommended in opioid-naïve patients. (It is

"President, Institute for Safe Medication Practices, 200 Lakeside Drive, Suite 200, Horsham, PA 19044; phone: 215-947-7797; fax: 215-914-1492; e-mail: mcohen@ismp.org; Web site: www.ismp.org. ${ }^{\dagger}$ Vice President, Institute for Safe Medication Practices, Horsham, Pennsylvania. 
uncertain whether this patient was opioid-tolerant, but if not, even a $1.5 \mathrm{mg}$ dose per hour would likely be enough to cause serious problems, given its equivalence to more than $10 \mathrm{mg}$ of morphine per hour.)

Further, it appears that the patient was not being monitored as recommended by the Anesthesia Patient Safety Foundation (APSF) with continuous electronic monitoring of oxygenation (pulse oximetry, monitored from a central location if possible) and intermittent nurse assessments (http://www.apsf.org/newsletters/ html/2007/winter/01_opioids.htm). Other modalities that measure ventilation and airflow adequacy (eg, capnography) should be used for patients who need supplemental oxygen to maintain acceptable oxygen saturation levels. Nurses should also be educated regarding safe dose ranges with the opioids used for PCA. Finally, use of a preprinted or electronic order set may help guide an appropriate dosing regimen for PCA.

\section{LIFE-THREATENING ERRORS WITH FLECAINIDE SUSPENSION IN CHILDREN}

Flecainide is an oral class $1 \mathrm{c}$ antiarrhythmic drug that may be used to treat atrial fibrillation or supraventricular tachycardia, particularly when conventional treatment agents fail. Because it is available commercially only as $50 \mathrm{mg}, 100 \mathrm{mg}$, and $150 \mathrm{mg}$ tablets, it must be compounded into a suspension when needed for infants and small children. Unfortunately, errors during preparation and dosing of the suspension have occasionally led to serious overdoses that resulted in cardiac emergencies and required immediate therapeutic intervention. Overdoses can lead to seizures and cardiotoxicity, including ventricular tachycardia and fibrillation due to sodium channel blockade. ${ }^{1}$ Treatment includes sodium bicarbonate boluses or sodium chloride boluses and extracorporeal circulatory support.

We first learned of a flecainide suspension-related error from a report submitted to ISMP in 2007. A 4-month-old infant had been receiving $8 \mathrm{mg}$ twice daily as an $8 \mathrm{mg} / \mathrm{mL}$ suspension ( $1 \mathrm{~mL}$ per dose). When the dose was later increased to $10 \mathrm{mg}$, a suspension purported to be $10 \mathrm{mg} / \mathrm{mL}$ was compounded. However, the baby's mother complained that the suspension was too thick to withdraw from the bottle. The pharmacist asked the mother to return the suspension and elected to compound a $7 \mathrm{mg} / \mathrm{mL}$ suspension, instructing the parent to give $1.4 \mathrm{~mL}$ per dose. Due to a math error, this replacement suspension was actually compounded with $6 \mathrm{~g}(6,000 \mathrm{mg})$ of flecainide instead of $600 \mathrm{mg}$. Therefore, each dose represented
$100 \mathrm{mg}$, not $10 \mathrm{mg}$. It is unclear whether the previous $10 \mathrm{mg} / \mathrm{mL}$ suspension may also have been prepared incorrectly.

Additional errors with compounded flecainide suspension have appeared in the literature..$^{1-5} \mathrm{~A}$ 2 -year-old child received a 5 -fold overdose when unlabeled oral syringes of nadolol (Corgard) and flecainide were used. Instead of withdrawing $5 \mathrm{~mL}$ of nadolol suspension (concentration not specified) and $1 \mathrm{~mL}$ of flecainide suspension $(20 \mathrm{mg} / \mathrm{mL})$, the nurse administered the opposite and the child received $5 \mathrm{~mL}$ of flecainide $(100 \mathrm{mg}){ }^{2}$ In another case, a pharmacy dispensed a $5 \mathrm{mg} / \mathrm{mL}$ suspension for a 4-week-old child who was supposed to receive $3 \mathrm{mg} / 0.6 \mathrm{~mL}$ three times a day. Pharmacy staff erroneously transcribed the dosing instructions to take " $3 \mathrm{~mL}$ " instead of $3 \mathrm{mg}(0.6 \mathrm{~mL})$, resulting in an overdose that led to wide complex tachycardia. ${ }^{3}$ In a third case, an 18-day-old infant received 4 doses of flecainide $8 \mathrm{mg}(0.8 \mathrm{~mL}$ of a $10 \mathrm{mg} / \mathrm{mL}$ suspension $)$ instead of $4 \mathrm{mg}(0.8 \mathrm{~mL}$ of a $5 \mathrm{mg} / \mathrm{mL})$, also resulting in wide complex tachycardia and cardiac arrest from which the child recovered. ${ }^{4} \mathrm{~A}$ fourth case involved a 9-month-old infant whose parents were told to increase the dose of flecainide to $4 \mathrm{~mL}$, assuming the concentration was $5 \mathrm{mg} / \mathrm{mL}$ as in the original prescription. ${ }^{1}$ The parents refilled the prescription at another pharmacy, receiving the drug in a $20 \mathrm{mg} / \mathrm{mL}$ concentration. The patient received $80 \mathrm{mg} / 4 \mathrm{~mL}$, a 4-fold overdose, resulting in wide complex tachycardia and QRS prolongation. Finally, an event published in December 2014 described an error in which the aunt of a 7-month-old child unknowingly gave him a 5 -fold overdose of flecainide. ${ }^{5}$ She pulled the suspension into an oral syringe that had both a teaspoon and $\mathrm{mL}$ scale and measured $5 \mathrm{~mL}$ (1 teaspoon) instead of $1 \mathrm{~mL}$. The child was hospitalized and suffered a cardiac arrest but was successfully resuscitated. Fortunately, all of the children recovered without neurologic sequelae following lifethreatening flecainide overdoses.

Unrecognized changes in drug concentration, math errors, labeling errors, and inaccurate dosing instructions led to the confusion in these cases. In one case, the authors indicated that all of their local pharmacies had agreed to compound flecainide in one standard concentration of $20 \mathrm{mg} / \mathrm{mL} .{ }^{1}$ Along this line, a Michigan state-wide initiative agreed to standardize the flecainide concentration and other compounded liquid medication concentrations for pediatric patients. The initiative, which received a 
2014 ISMP Cheers Award, provides the preparation directions, final concentration, stability data, storage information, and information for prescribers and families about the standards. ${ }^{6}$ Such efforts to standardize concentrations in both inpatient and outpatient pharmacies can help eliminate medication errors like those described above. The American Society of Health-System Pharmacists (ASHP), in cooperation with ISMP, the US Food and Drug Administration (FDA), and other stakeholders, is trying to broaden this initiative nationwide.

To reduce the risk of errors, prescribers should order flecainide in terms of the mg dose. This allows pharmacists to address the suspension concentration $(\mathrm{mg} / \mathrm{mL})$ and volume per dose, which should be expressed in $\mathrm{mL}$ (metric). For neonates and infants, a lower concentration may be required. If the drug is prescribed by volume $(\mathrm{mL})$, the concentration MUST be specified, or the prescriber must be contacted for clarification.

In hospitals, pharmacy labels should specify the dose in terms of both $\mathrm{mg}$ and $\mathrm{mL}$, followed by the concentration, such as "flecainide $5 \mathrm{mg}(0.25 \mathrm{~mL})$ $20 \mathrm{mg} / \mathrm{mL}$ suspension." The pharmacy should dispense all doses in patient-specific oral syringes. In ambulatory care, when dispensing the medication, the retail pharmacy should provide liquid suspensions with a flow restrictor embedded in the neck of the bottle (Figure 1) along with an oral syringe with which to measure and administer doses. Be sure to remind the patient or parents to secure the childresistant cap after each use. Label directions should include the dose in terms of $\mathrm{mL}$, such as "flecainide $0.25 \mathrm{~mL}$ by mouth every 8 hours." Purchase and use of mL-only oral syringes is an ISMP Targeted Medication Safety Best Practice (http://www.ismp. org/tools/bestpractices/TMSBP-for-Hospitals.pdf). The ambulatory care pharmacy label should also include the concentration next to the drug name, below the instructions for use. To be sure parents give a proper dose, use "teach-back" methods to demonstrate how to measure and administer proper amounts. This also gives pharmacists and parents an opportunity to catch an error.

\section{REFERENCES}

1. Wang GS, Tham E, Maes J, Buchanan JA. Flecainide toxicity in a pediatric patient due to differences in pharmacy compounding. Int J Cardiol. 2012;161(3):178-179.

2. D'Alessandro CD, Rieder MJ, Gloor J, Freeman D, Buffo-Sequiera I. Life-threatening flecainide intoxication in a young child secondary to medication error. Ann Pharmacother. 2009;43(9):1522-1527.

3. Riley B, Judge B, Veltman M. Flecainide toxicity in a newborn. 2014 Annual Meeting of the North American Congress of Clinical Toxicology (NACCT). Clin-Toxicol (Phila). 2014;52(7):802-803.

4. Jang D, Hoffman R, Nelson L. A case of near-fatal flecainide overdose in a neonate successfully treated with sodium bicarbonate. J Emerg Med. 2013;44(4):781-783.

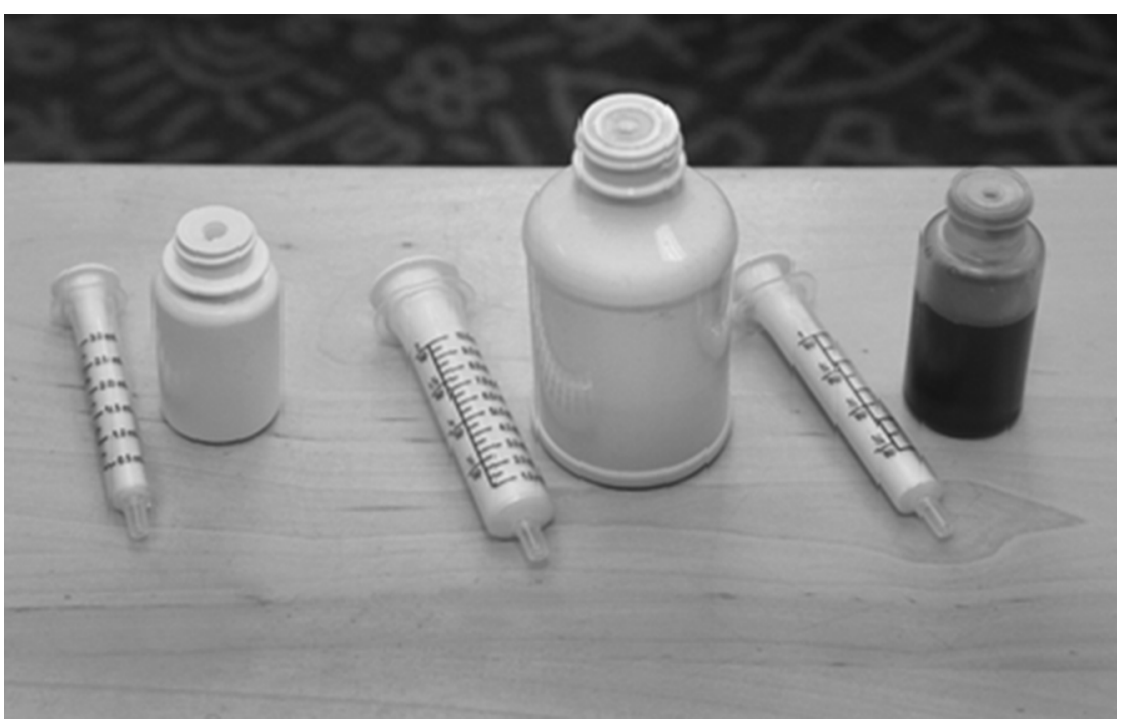

Figure 1. Flow restrictors in neck of medication bottles, along with and oral syringes. 
5. Kwan D, Vohra R, Dyer JE, Dornhoffer P. An infant with a heartbreaking medication error. Pediatr Emerg Care. 2014; 30(12):e1-5.

6. Michigan Pediatric Safety Collaboration. Flecainide acetate suspension. Michigan Collaborative Standardization of Compounded Oral Liquids. March 2014. www.ismp.org/ sc?id=518

\section{MEDICAL PRODUCT ERROR-PREVENTION EFFORTS NEED TO BE SHARED AND HARMONIZED INTERNATIONALLY}

Unsafe labeling, packaging, and product information can sometimes be imported into the United States by global pharmaceutical companies. In medical journals and advertising mailed to many of us earlier this year, Sanofi expressed the strength of their new high concentration insulin product Toujeo as “300U/mL" (Figure 2).

Not only is the abbreviation " $U$ " discouraged in the United States, but the lack of a space between 300 and $U$ sets a terrible example for prescribers and electronic prescribing system vendors who might be unaware that this practice might lead to a dangerous, 10-fold insulin overdose. Sanofi is a French company that has done business in the United States for many years. So, it is disappointing that US executives were unaware of the potential for an overdose when abbreviating units with a "U" (and that The Joint Commission has "U" on their "Do Not Use" abbreviation list) or were otherwise powerless to stop an ad campaign designed in France. Thankfully, when this was brought to their attention, all labeling and advertising materials were revised (Figure 3).

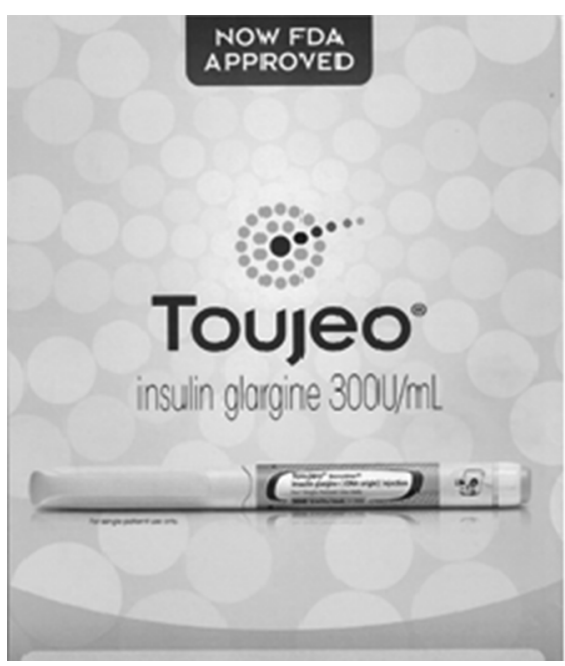

Figure 2. Former display ad for Toujeo.

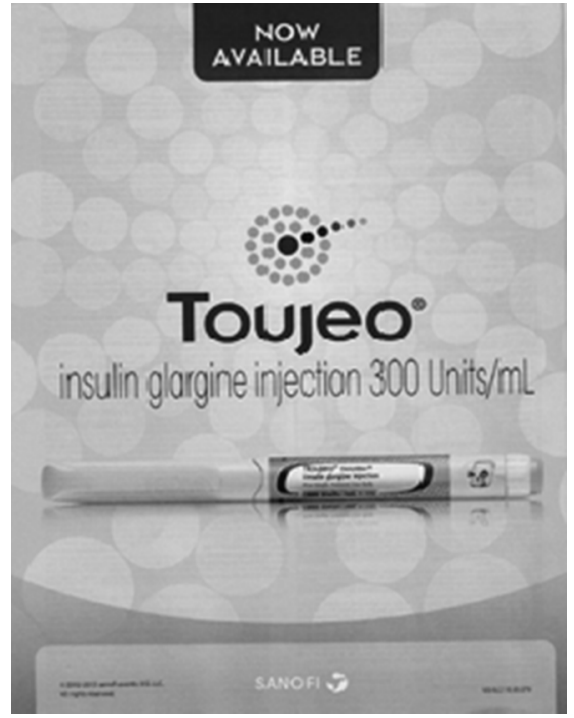

Figure 3. Revised Toujeo display ad.

Two other foreign medication error issues came to our attention recently through a patient safety journal, Prescrire. In France, a phenobarbital liquid product known as Kaneuron had, until recently, a dosing device with a dual scale-drops and $\mathrm{mL}$. This led to erroneous conversion of the number of drops into $\mathrm{mL}$ in 4 infants. The overdoses in 3 infants resulted in drowsiness and hypotonia, but no serious harm. The fourth infant experienced apnea and a coma and required hospitalization. The outcome of this infant is unknown. The Kaneuron oral dosing device was recently changed and now measures only in drops. (It is not known why the company chose drops instead of $\mathrm{mL}$, because the majority of countries use the metric system.) Also in France, topical minoxidil poisoning occurred because the manufacturer-supplied liquid lacked a child-protective safety cap. A 3-yearold ingested the medication meant for her father. The child's face and ears first became flushed and then she started vomiting and experienced significant hypotension. The adverse effects subsequently resolved.

It is going to be impossible for health care organizations to create highly reliable patient safety systems without the pharmaceutical and medical device industry joining them on this critically important journey. More than $25 \%$ of all medication errors reported to the ISMP National Medication Errors Reporting Program are product-related. There is an even higher percent of product-related errors among medication errors reported to the ISMP National Vaccine Errors Reporting Program. Not enough attention is paid to 
medication errors globally by regulatory authorities and industry. Too often, companies are shortsighted and fail to see how important product safety issues that lead to errors in one country can lead to errors in other countries. They may repeat the same dangerous practices that have led to patient harm in one country, instead of addressing the issue on a global scale. Improvement will require that regulatory authorities throughout the world take the lead, as the FDA and Health Canada have been doing in North America with the help of ISMP and ISMP Canada.

This brings us to the reason for mentioning all of this. Earlier this year, the European Medicines Agency (EMA) released 2 draft good practice guides (www.ismp.org/sc?id=511) that aim "to improve the reporting, evaluation and prevention of medication errors by regulatory authorities and pharmaceutical industry throughout the EU." One guide describes the main sources and types of medication errors and proposes measures to minimize their risk throughout the life cycle of a medication. The other guide provides direction on how manufacturers should record, code, report, and assess suspected adverse reactions that are caused by medication errors. An addendum to these that focuses on the risk of medication errors linked to new high-strength insulin and insulin products addressed not using the error-prone abbreviation "U."

These guides are an important "next step" in ensuring that common product-related medication errors are addressed worldwide, a goal of the International Medication Safety Network (www.intmedsafe. net), whose members actively participated in deliberations that led to the guidances in Europe. The action will enhance efforts in Spain (ISMP Spain), France (Prescrire), and the United Kingdom (National Health Service), all of which already have reporting programs. It will also help in North America and in other countries around the world, as data from all of the reporting and safety programs can be shared. With this effort, we can learn from one another and eventually harmonize medical product error-prevention efforts internationally. 